\title{
Spontaneous air space enlargement in the lungs of mice lacking tissue inhibitor of metalloproteinases-3 (TIMP-3)

\author{
Kevin J. Leco, ${ }^{1}$ Paul Waterhouse, ${ }^{2}$ Otto H. Sanchez, ${ }^{1}$ Katrina L.M. Gowing, ${ }^{1}$ \\ A. Robin Poole, ${ }^{3}$ Andrew Wakeham, ${ }^{2}$ Tak W. Mak, ${ }^{2}$ and Rama Khokha ${ }^{1}$ \\ ${ }^{1}$ Ontario Cancer Institute, University of Toronto, Toronto, Ontario, Canada \\ ${ }^{2}$ Amgen Inc., and Ontario Cancer Institute, University of Toronto, Toronto, Ontario, Canada \\ ${ }^{3}$ Shriner's Hospital for Children and Division of Surgical Research, Department of Surgery, \\ McGill University, Montreal, Quebec, Canada
}

Address correspondence to: Rama Khokha, Department of Medical Biophysics,

Ontario Cancer Institute, 610 University Avenue, Toronto, Canada M5G 2M9.

Phone: (416) 946-2051; Fax: (416) 946-2984; E-mail: rkhokha@oci.utoronto.ca.

Kevin J. Leco' s present address is: Department of Physiology, University of Western Ontario, London, Ontario, Canada.

Paul Waterhouse's present address is: GlycoDesign, Toronto, Ontario, Canada.

Received for publication December 21, 2000, and accepted in revised form August 3, 2001.

\begin{abstract}
Tissue inhibitors of metalloproteinases regulate ECM degradation by matrix metalloproteinases (MMPs). We have developed a mouse line deficient for tissue inhibitor of metalloproteinases-3 (TIMP3), the only TIMP known to reside within the ECM. Homozygous Timp-3-null animals develop spontaneous air space enlargement in the lung that is evident at 2 weeks after birth and progresses with age of the animal. As early as 13 months of age animals become moribund. Lung function, measured by carbon monoxide uptake, is impaired in aged null animals. Lungs from aged null animals have reduced abundance of collagen, enhanced degradation of collagen in the peribronchiolar space, and disorganization of collagen fibrils in the alveolar interstitium, but no increase in inflammatory cell infiltration or evidence of fibrosis in comparison with controls. Using in situ zymography, we show that lungs from aged null animals have heightened MMP activity over wild-type and heterozygotic animals. Finally, TIMP-3-null fibroblast cultures demonstrate enhanced destruction of ECM molecules in vitro. We propose that the deletion of TIMP-3 results in a shift of the TIMP/MMP balance in the lung to favor ECM degradation, culminating in incapacitating illness and a shorter life span.
\end{abstract}

J. Clin. Invest. 108:817-829 (2001). DOI:10.1172/JCI200112067.

\section{Introduction}

The ECM is a dynamic structure that not only provides a scaffold organizing tissue structure, but also contributes signals that regulate cell conduct and homeostasis. Composition of the ECM, its three dimensional structure, and proteolytic remodeling all contribute to the cellular microenvironment that controls cell growth, shape, motility, differentiation, and survival (1). The matrix metalloproteinases (MMPs) represent a family of zinc-dependent, ECM-degrading endopeptidases, which together can cleave all the protein components of the $\operatorname{ECM}(2,3)$. The tissue inhibitors of metalloproteinases (TIMPs) are physiological protein inhibitors of MMPs, of which there are now four distinct family members known $(4,5)$. It is believed that matrix remodeling is the result, in part, of a shift in the balance between active MMPs versus TIMPs, and coordinate regulation of these families of molecules is required to maintain tissue architecture (1-3). Normal processes requiring controlled changes in MMP and TIMP levels include wound healing $(6)$, ovulation $(7,8)$, embryo implantation (9-12), and mammary develop- ment and involution (13-15). Local disruption of the normal balance favoring the MMPs has been implicated in diverse pathological states such as arthritis (2), cardiovascular disease (16), tumor invasion and metastasis $(17,18)$, and emphysema $(19,20)$.

We have sought to upset the MMP/TIMP balance in the whole animal by disrupting expression from the Timp-3 gene. TIMP-3 was first identified as a protein associated with the ECM expressed during oncogenic transformation of chicken embryo fibroblasts (21). Subsequent isolation of the cDNA encoding the chicken transformation-sensitive protein identified it as a member of the TIMP family of proteins (22). Mammalian TIMP- 3 is a secreted protein that localizes to the ECM $(23,24)$ and is able to inhibit MMP-1, $-2,-3$, and -9 with equal efficiency (25). Expression studies have detected the mRNA encoding murine Timp-3 in the maternal decidua during embryo implantation (9-12), in cartilage, muscle, skin, numerous epithelial layers, and in the placenta during embryogenesis (26). In the adult animal, prominent sites of expression include kidney, lung, heart, ovary, brain, and mammary tissue $(4,13,23,26)$. 
Yang and Hawkes described TIMP-3 as a mitogen for chicken embryo fibroblasts under serum-reduced conditions. It was hypothesized that addition of TIMP-3 to cultured cells maintained the integrity of the ECM, thereby supporting cell growth via ECM-binding growth factors (27). Others have shown that antisense downregulation of TIMP-3 expression in leiomyosarcoma cells resulted in enhanced proliferation of the cells in culture (28). Alternatively, several studies have reported that overexpression of TIMP-3 results in enhanced apoptosis in transformed cells (29-32) and nontransformed cells $(33,34)$ in vitro and in vivo $(34)$. Bond and coworkers localized the proapoptotic domain of TIMP-3 to the N-terminal three loops of the protein. Notably, the presence of a functional MMP inhibitory activity is required for induction of apoptosis (35).

Recently, it has been demonstrated that TIMPs are efficient inhibitors of some members of the class of cell surface proteinases termed ADAMs (a disintegrin and a metalloproteinase domain). ADAMs appear to be involved in cellular processes such as disruption of cell adhesion, cleavage of ECM molecules, and shedding of cell surface proteins $(36,37)$. The in vitro proteolytic activity of ADAM-10 can be inhibited by TIMPs- 1 and -3 , but not TIMP-2 and -4 (38). TIMP-3 is an efficient inhibitor of ADAM-TS4, considerably superior to TIMP$1,-2$, and -4 (39), while the N-terminal domain of TIMP3 is a potent inhibitor of both ADAM-TS4 and -TS5, which are postulated to cleave aggrecan, a component of cartilage matrix (40). Other members of the ADAM family are inhibitable only by TIMP-3. For example, TIMP-3 can inhibit ADAM-12S-mediated cleavage of IGFBP-3 and -5 (41), and TNF- $\alpha$-converting enzyme (TACE; ADAM-17) is specifically inhibited by TIMP-3 or the $\mathrm{N}$-terminal domain of TIMP-3, but not by TIMP-1, -2, or $-4(42,43)$. Shedding of other cell surface molecules (TNF- $\alpha$ receptor, IL- 6 receptor, L-selectin, syndecan- 1 and -4 , and c-Met) by TIMP-3-sensitive metalloproteinases have been reported; however, the identity of the "sheddases" was not confirmed (31, 44-47).

Mice with a targeted deletion of TIMP-1 have been developed. Host TIMP-1 deficiency does not influence lung tumor invasion (48), nor does it affect ovulation (49) or renal fibrosis in response to protein overload or ureter obstruction $(50,51)$, however it does have a minor effect on testicular production of testosterone (52). More obvious effects of TIMP-1 deficiency were observed in the reproductive cycle of female mice (53), resistance to bacterial eye infection (54), arterial neointima formation after vascular injury (55), left ventricular geometry and function (56), and retinal neovascularization (57). More recently, TIMP-2-null mice have been described. Although no obvious defect in TIMP-2-deficient mice was found, lack of TIMP-2 altered the processing of pro-MMP-2, with TIMP-2 being required for efficient activation of pro-MMP-2 both in vivo and in vitro $(58,59)$.

As an approach to better understand the functions of the TIMP-3 protein, we generated a TIMP-3-deficient mouse by homologous recombination. TIMP-3-null animals spontaneously develop progressive alveolar air space enlargement with a concomitant impaired capacity for gas exchange. At the biochemical level there is a reduction in the collagen content in aged null lungs compared with controls. Furthermore, we provide histological evidence for collagen type-I degradation and functional evidence of elevated MMP activity in situ in the absence of the TIMP-3 protein. All of these features of the null animal contribute to a phenotype that confers premature morbidity and mortality.

\section{Methods}

Generation and characterization of TIMP-3-null mice. A genomic $\lambda$ library from $129 /$ Ola embryonic stem (ES) cells was plated according to standard procedures (60) and probed with a $1.8-\mathrm{kb}$ Timp-3 cDNA (23). Eight $\lambda$ clones were plaque purified, of which one contained promoter and exon 1 sequences and one contained exons 2 and 3 of the Timp-3 genomic locus (25). PCR with PfuI DNA polymerase was employed to produce two fragments of the Timp-3 gene with which to make the targeting construct. The 723-bp "short arm" contains 5' DNA sequences from -459 to +264 (numbering based upon ref. 61), which end 52 bp upstream of the AUG translation initiation codon. The approximately 6-kb "long arm" consists of sequences from 453 of exon 2 through 560 of exon 3 , including the entire second intron (numbering based on the Timp-3 cDNA; ref. 23). The long and short arms were subcloned into the pBS-neo vector (62) such that the $\mathrm{Neo}^{R}$ gene replaced the deleted sequences of the Timp-3 gene in the opposite transcriptional orientation. All sequences from upstream of the translation initiation site through the conserved VIRAK codons were deleted in the construct. The targeting construct was introduced into 129/Ola ES cells by electroporation and neomycinresistant colonies selected. Three independent properly targeted clones were isolated. Homologous recombination was confirmed by restriction digestion of ES cell genomic DNA with SacII and XhoI, followed by Southern blot analysis with a 300-bp fragment of the Timp-3 cDNA external to the targeting construct using standard procedures (60). Subsequent genotyping of animals was achieved by PCR analysis (not shown). Heart, kidney, and lung RNA was prepared from wild-type, heterozygotic, and null mice by the method of Chomczynski and Sacchi (63) for Northern blot analysis, using $1.8 \mathrm{~kb}$ Timp-3 cDNA (23) and the Neo $o^{R}$ gene as probes. Kidney extracts enriched for the TIMP-3 protein were prepared by grinding the tissue in a glass homogenizer in 10 volumes (volume to weight) of a buffer containing $50 \mathrm{mM}$ TRIS-Cl, pH 7.5, 1\% Triton $\mathrm{X}-100,2 \mathrm{mg} / \mathrm{ml}$ leupeptin, $1 \mathrm{mg} / \mathrm{ml}$ pepstatin, and 100 mM PMSF. Samples were centrifuged at $800 \mathrm{~g}$, and the pellet (ECM fraction) was then extracted with 5 volumes of a buffer containing 50 mM Tris-Cl, pH 7.5, 200 $\mathrm{mM} \mathrm{NaCl}, 1 \% \mathrm{SDS}$, and proteinase inhibitors as above. Following centrifugation at $16,000 \mathrm{~g}, 5 \mu \mathrm{l}$ of the super- 
natant was mixed with $5 \mu \mathrm{l}$ of $2 \times$ SDS-PAGE gel-loading buffer and electrophoresed on a $12 \%$ discontinuous SDS-PAGE gel (60). Reverse zymographic analysis was performed as described previously (23). Animals were cared for in accordance with the protocols approved by the OCI Animal Care Committee, following the guidelines of the Canadian Council on Animal Care.

Lung histology. Animals at the various time points were sacrificed by terminal anesthesia. The right bronchus was clamped with a hemostat, and the three lobes of the right lung were removed and frozen for protein and hydroxy-proline content analysis. The left lobes were inflated and fixed by intratracheal instillation of $10 \%$ neutral buffered formalin at a constant pressure of 25 $\mathrm{cm}$ of water (10 cm of water for 2 -week animals) for 1 minute. The superior left lobe was cut in half lengthwise, then fixed for 24 hours before embedding in paraffin and sectioning at $7 \mu \mathrm{m}$. Sections were stained with hematoxylin and eosin and images captured at $200 \times$ using a Nikon DXM1200 color digital camera and Nikon E1000 microscope. For determination of mean linear intercept $(\mathrm{Lm})$, sections were examined without knowledge of genotype at 400x. Twenty random fields within approximately $100 \mu \mathrm{m}$ of the lung pleura from two different regions of the superior left lobe were examined by means of a $350-\mu \mathrm{m}$ straight line scale in the eyepiece of the microscope. The number of alveoli intersected by the line were counted, and the average alveolar size was calculated. Results were confirmed by an independent investigator. All statistical analyses in this report were performed with Microsoft Excel 2000, using a two-tailed student's $t$ test.

Lung function tests. Aged TIMP-3-null and control littermates were analysed for lung function by means of carbon monoxide (CO) uptake. Animals tested ranged in age from 50 to 57 weeks, with the mean age for both control and null groups being approximately 52 weeks at the start of the study. Results were obtained using an automated $\mathrm{CO}$ uptake measuring device (Columbus Instruments; Columbus, Ohio, USA). Four independent $\mathrm{CO}$ uptake measurements were taken over a period of 3 weeks.

Measurement of bydroxy-proline. Lungs from TIMP-3null and control littermates were tested for hydroxyproline content as an estimate of collagen content. Samples were prepared according to the technique of Naum and Morgan (64) and subjected to a hydroxyproline assay (in triplicate) as described previously (65). Values obtained were normalized to the DNA content of the tissues.

Histological staining. Paraffin sections were stained with either Masson's trichrome stain to visualize collagen, Ab's raised against collagen type-I neoepitopes to visualize fragmented collagen, Movat's stain to visualize elastin fibers, or $\alpha M M P-12$ Ab's (a kind gift from Steven Shapiro, Washington University, St. Louis, Missouri, USA). Staining was performed by the pathology laboratory at the Ontario Cancer Institute using standard procedures.
Transmission electron microscopy. Transmission electron microscopy (TEM) was performed by the Electron Microscopy Laboratory, University of Toronto. Fresh lung tissue was isolated, cut into $1-\mathrm{mm} \times 1-\mathrm{mm}$ cubes, and fixed in $2.5 \%$ glutaraldehyde and $4 \%$ paraformaldehyde in PBS at $4^{\circ} \mathrm{C}$. Samples were treated (after being fixed) with tannic acid to highlight elastin fibers before embedding in resin. Ultrathin sections were examined under TEM and alveolar interstitium fields selected at random for micrographs under the direction of a pathologist (O.H. Sanchez).

Zymography and reverse zymography of bronchoalveolar lavage fluid. Animals at either 2 or 4 months of age were sacrificed by terminal anesthesia. The renal artery was severed prior to death, the diaphragm and rib cage cut to expose the lungs, and lungs inflated by intratracheal instillation of PBS at a constant pressure of $25 \mathrm{~cm}$ of water. The trachea was clamped with a hemostat, lungs removed, and bronchoalveolar lavage (BAL) fluid collected. Protein content of BAL samples was determined based on the method of Bradford (Bio-Rad Laboratories Inc., Hercules, California, USA). Equal amounts of protein (50 ng each) were loaded on a 10\% polyacrylamide gel with $1 \mathrm{mg} / \mathrm{ml}$ gelatin for zymography or a $10 \%$ gel with $1 \mathrm{mg} / \mathrm{ml}$ gelatin plus BHK cell-conditioned media (cells a gift from Dylan Edwards, University of East Anglia, Norwich, United Kingdom) as a source of MMPs for reverse zymography. After electrophoresis, gels were treated as described previously $(9,23)$. MMPspecific gelatinolytic activities were confirmed by incubation of a sample lane in $20 \mu \mathrm{M}$ GM6001 (Chemicon International, Temecula, California, USA).

Northern blot analysis. Heart, kidney, and lung RNA was prepared from wild-type, heterozygotic, and null mice (63) for Northern blot analysis (60). Timp cDNAs probes have been described previously $(4,23,66)$. Collagen type-I and type-IV probes were a gift from Michael Underhill (University of Western Ontario, London, Ontario, Canada).

In situ zymography. Fresh-frozen lung tissue sections were thawed and overlaid with $100 \mu \mathrm{g} / \mathrm{ml}$ fluoresceinconjugated DQ gelatin (Molecular Probes Inc., Eugene, Oregon, USA) in substrate buffer and LMP agarose as described previously (67). Glass coverslips were applied before agarose gelling, slides were incubated in a humid container at $37^{\circ} \mathrm{C}$ for 12 hours, and fluoromicrographs were captured using a 460- to 500 -nm light source and the microscopy equipment described above. The settings for light intensity and exposure time were identical for all samples. Digestion of gelatin releases the quenched fluorochrome, which can then be detected microscopically. Areas of fluorescence are indicative of gelatinolytic activity. Confirmation of MMP activity was achieved by incubation of a null sample slide with substrate in the presence of $20 \mu \mathrm{M}$ GM6001.

Fibroblast culture and immunoblotting. Matings were set up between Timp- $3^{+-}$animals, embryos collected at day 16.5 , and fibroblast cultures were prepared. One wildtype and one null primary embryonic fibroblast culture were immortalized by serial passage and both lines were 

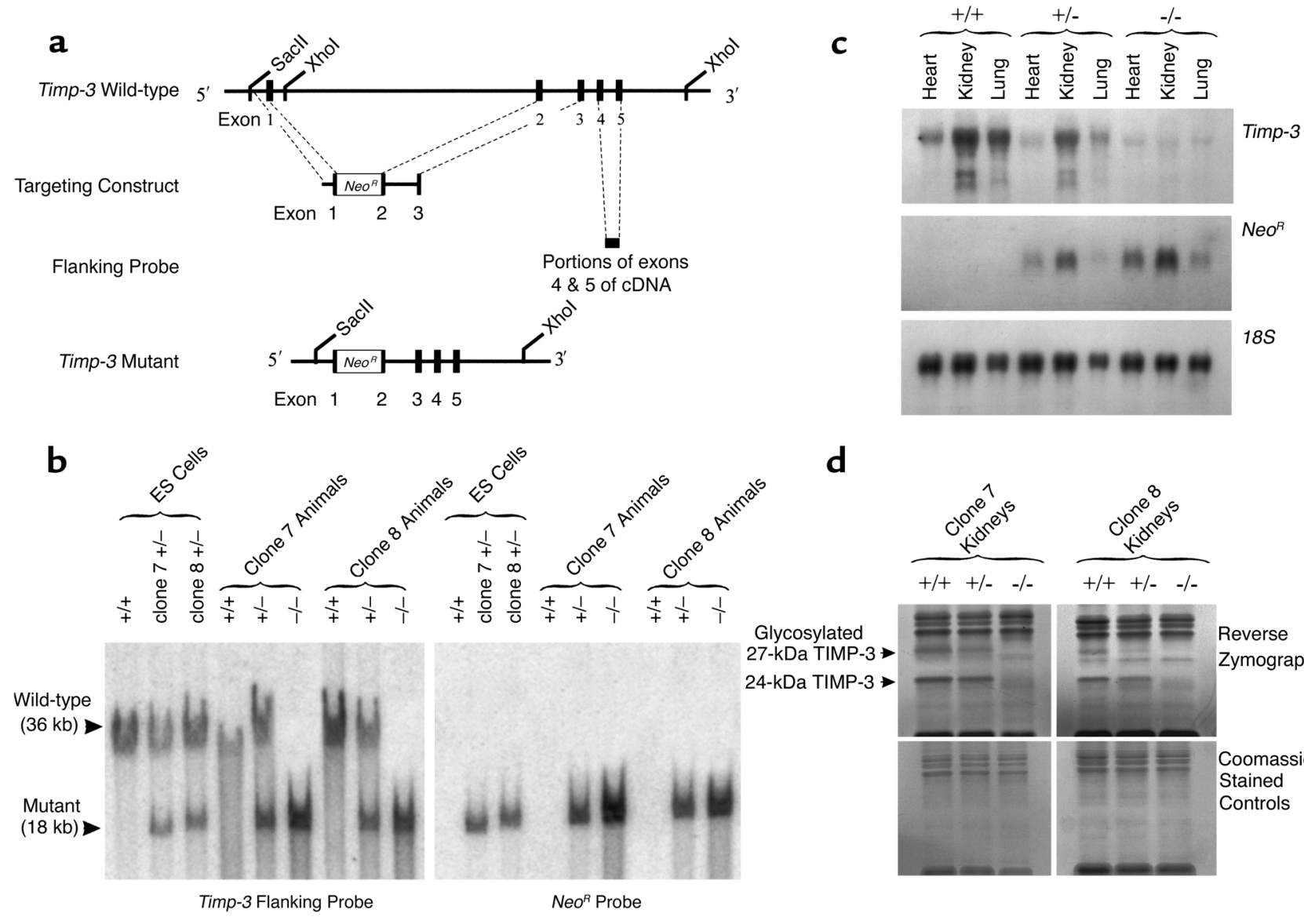

d

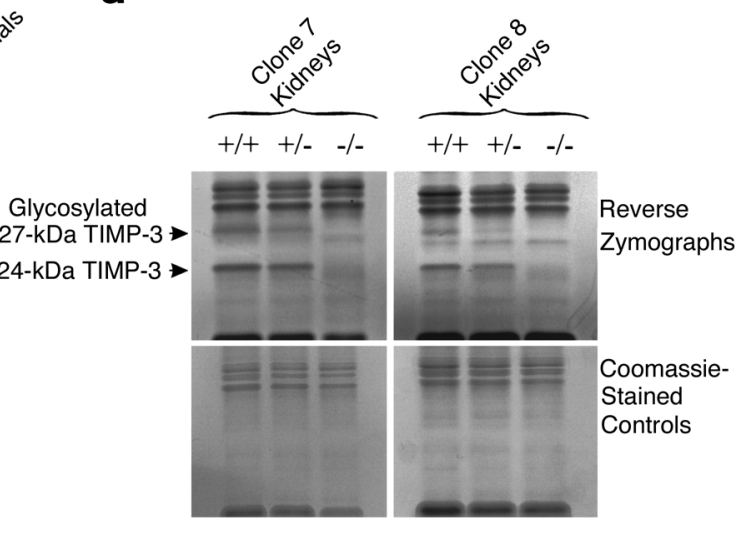

\section{Figure 1}

Generation of TIMP-3-null animals. (a) Targeting strategy: Approximately 700 bp of Timp-3 promoter sequence and $6 \mathrm{~kb}$ from exons 2 and 3 (including the second intron) were placed on either side of a $\mathrm{Neo}^{R}$ cassette in the opposite transcriptional orientation. (b) Southern blot analysis: A flanking Timp-3 or Neo $o^{R}$ DNA probe detected the mutant allele $(18 \mathrm{~kb})$ in heterozygote ES cells and heterozygote and null animals. (c) Northern blot analysis: Abundance of the Timp-3 mRNA was reduced in heterozygote and null animals while expression of a Neo ${ }^{R}$ mRNA (evidently under the tissue-specific direction of the TIMP-3 promoter) was detected in heterozygote and null animals. (d) Reverse zymographic analysis: TIMP-3 protein was reduced in heterozygotic kidney extracts by approximately half compared with wild-type and was absent in the null extracts.

used at passage 28. Cells $\left(10^{6}\right)$ were seeded on $10-\mathrm{cm}$ dishes in DMEM:F12 supplemented with 1\% FCS and allowed to attach to the dish. After 2 hours, media was changed to serum-free DMEM:F12, and the cultures incubated an additional 24 hours (all tissue culture media and supplements were from Life Technologies Inc., Rockville, Maryland, USA). Null cells were incubated $\pm 20 \mu \mathrm{M}$ GM6001. ECM fractions were isolated as described (23). Equivalent quantities of ECM from null or wild-type cultures were loaded on an $8 \%$ discontinuous SDS-PAGE gel (60) and blotted to nitrocellulose membranes (Amersham-Pharmacia Biotech, Piscataway, New Jersey, USA). Individual filters were incubated with Ab's directed against collagen type-I (rabbit anti-mouse polyclonal; 1:1,000 dilution; Chemicon International) or collagen type-IV (mouse monoclonal; 1:1,000 dilution; Oncogene Research Products, Cambridge, Massachusetts, USA), washed in TBS-T, incubated with antimouse or anti-rabbit secondary Ab's conjugated with horseradish peroxidase (1:5,000 dilution; Life Technologies Inc.), washed in TBS-T. Bands were visualized autoradiographically on X-AR film (Eastman Kodak Scientific Imaging Systems, New Haven, Connecticut, USA) by chemiluminescence with enhanced chemiluminescence (ECL) reagent as described by the manufacturer (Amersham Pharmacia Biotech).

\section{Results}

Generation of Timp-3-null mice. A targeting vector was constructed that deleted all of the sequence from just upstream of the initiation codon in exon 1 of the Timp3 gene through the VIRAK codons within exon 2; the latter being a hallmark motif conserved in all TIMP proteins reported to date (4). These sequences were replaced with a neomycin resistance reporter gene $\left(N e o^{R}\right)$ placed in the opposite transcriptional orientation (Figure 1a). Thus, the translation initiation sequence as well as sequences encoding amino acids important for TIMP inhibitory activity $(35,68)$ were deleted in the vector. Two independently targeted 129J/Ola embryonic stem cell lines (clone 7 and clone 8 ) were introduced into C57BL/ 6 blastocyst stage embryos by microinjection 
and the blastocysts transferred to pseudopregnant foster mothers. Resultant chimeric males were mated to wild-type C57BL/ 6 females and brown pups screened by PCR for transmission of the recombinant allele. Mutant alleles from both clones were successfully transmitted to produce heterozygotic Timp-3-null animals. Heterozygotic males and females $(129 \mathrm{~J} / \mathrm{Ola} \times \mathrm{C} 57 \mathrm{BL} / 6)$ were then crossed to produce wild-type, heterozygotic, and null animals. In addition heterozygotic males and null females (and vice versa) were also crossed to produce heterozygotic and null offspring. Both the wildtype and heterozygotic animals produced in these crosses were used as controls for all subsequent experiments. Null and control animals had the same genetic background. Southern blot analysis of the two independent ES cell clones and subsequent mouse lines demonstrated homologous targeting events (Figure 1b). Northern blot analysis using RNA isolated from heart, kidney, and lung demonstrated an approximately one-half reduction of Timp-3 mRNA in the heterozygotes as compared with wild-type and an absence of Timp-3 mRNA in null animals (Figure 1c). The faint signal seen in the null lanes apparently represents hybridization to ribosomal RNA, because extensive RT-PCR analysis could not detect any Timp-3 mRNA in these samples (not shown). Furthermore, reverse zymographic analysis of kidney ECM extracts established that the TIMP-3 protein activity was similarly reduced to half in heterozygotes and absent in null animals (Figure 1d).

Matings between heterozygous mice produced 23\% wild-type, $57 \%$ heterozygotic, and $20 \%$ null animals for clone 7 and $30 \%$ wild-type, $57 \%$ heterozygotic, and $13 \%$ null animals for clone 8 . While the number of null animals is less than the expected Mendelian distribution of $25 \%$, crosses between heterozygotic males and null females (and vice versa) produced approximately $46 \%$ heterozygotic and $54 \%$ null offspring, indicating that the null mutation is not embryonic lethal and that null parents are fertile. Null animals are also viable and fertile after backcrossing into a C57BL/6, CD1, or FVB mouse background. Finally, no significant size difference between null and wild-type pups nor weight differences in healthy adults has been noted.

TIMP-3 knockout mice demonstrate early mortality. Beginning at 13 months, some TIMP-3-null animals became overtly sick, displaying lethargy, hunched posture, ruffled fur, and labored breathing involving abdominal accessory muscles. Following the Canadian Council on Animal Care guidelines, and under the supervision of the veterinarian overseeing our facility, such animals were considered moribund, sacrificed, and submitted to autopsy. A survival curve for the TIMP-3 knockout animals is shown (Figure 2). The mean age of survival for male null animals was $62 \pm 6.4$ weeks $(n=10)$, and for null females the value was $72 \pm 7.6$ weeks $(n=10)$. As a group, the mean survival of TIMP-3-null mice was $67.3 \pm 8.4$ weeks. Heterozygous control animals showed no illness at age 120 weeks. In our laboratory, wild-type 129J/Ola $\times$
C57BL/6 mice bred for other purposes have lived for as long as 137 weeks (O. H. Sanchez and R. Khokha, unpublished data). Thus, the life span of mice lacking a functional Timp-3 gene is severely compromised.

TIMP-3 deficiency results in air space enlargement in the lung. Since Timp-3 mRNA is normally highly expressed in adult lung (refs. 4, 23; Figure 1c), we examined the lungs of TIMP-3-null animals for abnormalities. As early as 2 weeks of age, lungs of null animals showed air space enlargement compared with wild-type controls (Figure 3a). Quantification of alveolar size was performed by calculating the mean linear intercept $(\mathrm{Lm})$, a measure of the average space between opposing alveolar walls (Figure $3 b)$. A progressive increase in $L m$ was seen with increasing age in the lungs of knockout animals. Alveoli of null lungs were not homogeneously enlarged, since areas of alveolar enlargement were interspersed with areas of near normal alveolar size. However, at all ages examined average alveolar size was significantly increased in knockout animals compared with controls.

Data in this experiment were collected from both clone 7 and 8 animals for the 4- and 8-month time points. There was no significant difference in $\mathrm{Lm}$ between clone 7 and clone 8 null animals at either 4 or 8 months, indicating that the progression of air space enlargement occurred in both independently derived TIMP-3-null animal lines. Lungs from heterozygotic animals were not significantly different from wild-type animals at any age examined. In aged TIMP-3-null animals average alveolar size was increased by approxi-
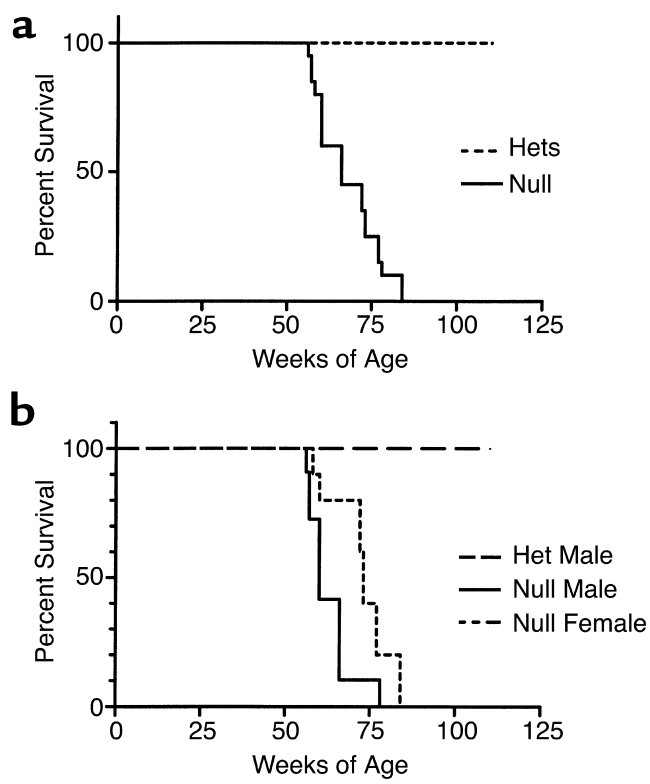

\section{Figure 2}

Survival of TIMP-3-null mice is compromised. (a) Beginning at 56 weeks of age, individual TIMP-3-null mice became overtly sick, and by 83 weeks of age all animals in this study were sacrificed. This compared with heterozygote controls (Hets), which lived illness free for at least 120 weeks. Shown is pooled data for both males and females. (b) Sex-specific differences in survival (TIMP-3-/- males, $n=10$; TIMP- $^{-/-}$females, $n=10$; TIMP- $^{+/-}$males, $\left.n=3\right)$. 

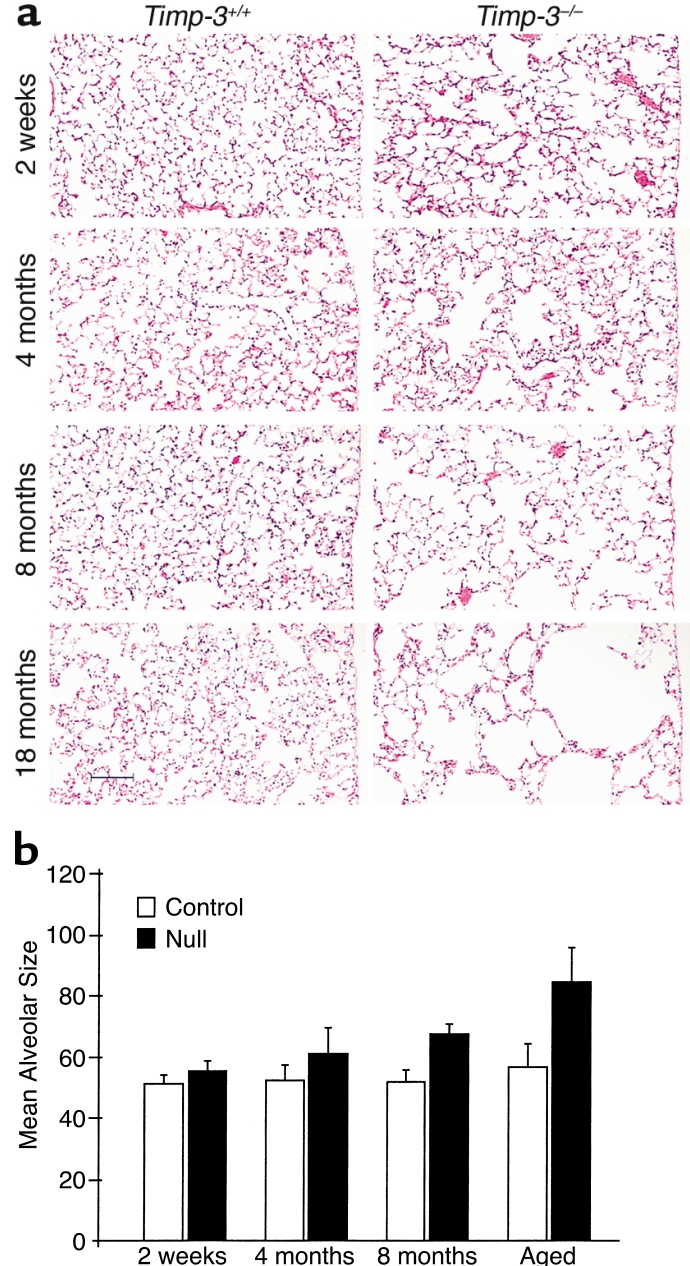

\section{Figure 3}

TIMP-3-null mice demonstrate alveolar air space enlargement. (a) Hematoxylin and eosin-stained lung sections (scale bar, $100 \mu \mathrm{m}$ ). (b) Quantification of mean linear intercept. A progressive increase in mean linear intercept was seen in the lungs of knockout animals, indicative of an increase in alveolar size with increasing age of the animal ( 2 weeks: control, $n=10$; null, $n=5 ; 4$ months: control, $n=10$; null, $n=6$; 8 months: control, $n=13$; null, $n=10$; aged: control, $n=17$; null, $n=20 ; \pm \mathrm{SD}$ ). At all ages examined, air space size was significantly increased in the knockout animals compared with controls (two-tailed Student's $t$ test; 2 weeks, $P<0.04 ; 4$ months, $P<0.03$; 8 months, $P<2 \times 10^{-10}$; aged animals, $\left.P<5 \times 10^{-10}\right)$.

mately $50 \%$ compared with controls. Aged TIMP-3-null animals refers to the group of animals defined in the survival curve (Figure 2). The ages at time of autopsy ranged from 56 to 83 weeks (mean age $67.3 \pm 8.4$ weeks), with littermates sacrificed at the same time for controls.

We also examined kidney and mammary tissue in young adult mice. No microscopic abnormality was evident in either of these tissues. Given the proapoptotic function associated with TIMP-3 overexpression (28-35), we investigated apoptosis in lung tissue using the TUNEL assay to detect fragmented nuclear DNA. Apoptosis was not observed in either the null or wild-type lung at all ages examined (2 weeks to aged). However, epithelial apoptosis was significantly accel- erated in involuting TIMP-3-null mammary gland (69). The eye, another prominent site of Timp-3 expression (70) in which Timp-3 is mutated in Sorsby fundus dystrophy (71), has yet to be carefully explored in TIMP-3-deficient animals.

Diminished lung function in TIMP-3-null animals. Uptake of carbon monoxide (CO) was measured as a test of lung function in aged animals. Impairment of gas exchange within the lung can be quantified by a reduction in CO diffusion across alveolar walls (72). Repeated exposure to low levels of $\mathrm{CO}$ produces no significant change in either respiratory function or life span of mice (73). Four independent CO-uptake measurements were taken at weekly intervals over a period of 3 weeks for a group of 18 control animals (10 female and 8 male, mean age 52 weeks) and 19 null littermates (10 female and 9 male, mean age 52 weeks), and results for each animal were averaged. As a group, male null animals showed a significant reduction of $18 \%$ in CO uptake when compared with controls, while female null animals displayed a $13 \%$ reduction (Table 1). No significant difference in $\mathrm{CO}$ uptake was noted between null and control animals at 8 weeks of age. These data link the pathological structural changes seen in the lungs of null animals to physiological impairment of lung function.

Destruction of ECM in the lung of TIMP-3-null animals. In an effort to understand the structural changes seen in the lungs of TIMP-3-null animals, we examined the composition of ECM in null and control lungs. Measurement of hydroxy-proline content of lung tissue (normalized to DNA) was employed as measure of total collagen content. The aged null animals examined displayed significantly less hydroxy-proline than did control littermates (Figure 4). Collagen content was reduced by approximately $32 \%$ in the aged null lungs. At 4 and 8 months of age a decline in hydroxy-proline content was seen in null lungs consistent with enlargement of alveoli (Figure 4), although the values were not statistically significant.

Given the biochemical difference in collagen content in aged null lungs, we further examined ECM components within the alveolar walls with differential stains under light microscopy (Figure 5). These micrographs reinforced our earlier finding of fewer alveolar walls in the absence of TIMP-3. Where alveolar walls were present, these contained similar amounts of collagen in TIMP-3-deficient animals and in controls as judged by intensity of Masson's trichrome stain (Figure 5, a and b). Similarly, differential staining of alveolar walls for elastin (Movat's stain) showed no decrease in elastin content in existing walls (Figure 5, e and f). The numbers of alveolar and interstitial macrophage cells were not altered in TIMP-3 knockout mice when immunohistochemically assessed using an $\mathrm{Ab}$ specific for murine macrophage metalloelastase (MMP-12; Figure 5, $\mathrm{g}$ and $\mathrm{h}$ ).

Intriguingly, when an $\mathrm{Ab}$ directed against collagen type-I cleavage fragments was used on TIMP-3-null lungs, we observed immunopositive staining in subepithelial areas of the terminal bronchioles indicative of 
Table 1

Lung function tests; uptake in control vs. Timp-3-1- mice

\begin{tabular}{lccc}
\hline Sample & $\begin{array}{c}\text { Control } \\
\text { CO uptake } \\
(\mu \mathrm{l} / \mathrm{min})\end{array}$ & $\begin{array}{c}\text { Null } \\
\text { CO uptake } \\
(\mu \mathrm{l} / \mathrm{min})\end{array}$ & $t$ test \\
Male & $18.6 \pm 1.3(8)$ & $15.3 \pm 1.6(9)$ & $P<0.04$ \\
Female & $17.3 \pm 0.8(10)$ & $15.1 \pm 1.1(10)$ & $P<0.02$ \\
$\begin{array}{l}\text { Male and } \\
\text { female }\end{array}$ & $17.9 \pm 1.1(18)$ & $15.2 \pm 1.3(19)$ & $P<0.002$
\end{tabular}

A Values represent mean $\pm \operatorname{SEM}(n)$

fragmentation of collagen type-I, although we did not observe staining in alveolar walls or perivascular areas (Figure 5, c and d). When an Ab specific for elastin was applied to the null lungs, we did not observe disruption of elastin layers either in alveolar walls, terminal bronchioles, or perivascular areas (not shown). We next explored whether the increased denatured collagen type-I in peribronchiolar areas was related to altered airway branching during development. The distance between terminal bronchioles and the pleural surface was measured and found to be significantly reduced in 2-week-old TIMP-3-null mice (49.6 \pm 0.6 units in null versus $59.5 \pm 2.5$ units in wild-type; $n=2, P<0.03$ ). This implies that there may be enhanced branching of the bronchiolar tree during embryonic development or that the branches are misdirected toward the pleural surface by altered epithelial/mesenchymal interactions during development.

Alveolar interstitium of TIMP-3-null and wild-type animals were examined at the ultrastructural level by transmission electron microscopy after tannic acid staining to highlight elastin fibers (Figure 6). Although elastin and interstitial collagen fibrils were present in alveolar walls, in some areas collagen bundles appeared in disarray (arrowheads). Basement membranes underlying type-I alveolar cells were found to be intact in the TIMP-3-null lung (arrows). Through these analyses we also confirmed the absence of an inflammatory response in the knockout lung tissue.

No altered MMP activation or TIMP compensation in TIMP-3-deficient animals. One potential mechanism underlying enlarged alveolar structures is increased MMP activity in the absence of TIMP-3. We performed BAL on 2- and 5-month-old animals and examined the BAL fluid for presence of MMP proteins. Gelatin zymographic analysis of BAL fluid (Figure 7a) revealed that the levels of expression of MMP-2 and MMP-9 were similar in both the control and null animals and that activation of these MMPs was not influenced by the absence of the TIMP-3 protein (active MMP-2 and -9 denoted by asterisks in Figure 7a). Incubation of a sample lane in the presence of a synthetic MMP inhibitor (GM6001) identified which gelatinolytic activities were MMPs. Western blot analysis with an MMP-12-specific Ab demonstrated the presence of fully active metalloelastase in the BAL fluid from both wild-type and null animals at comparable levels (not shown).
TIMP-3 is a specific inhibitor of ADAM-17 or TNF- $\alpha-$ converting enzyme (TACE; refs. 42, 43). We therefore examined the BAL fluid for the presence of TACE and soluble TNF- $\alpha$ by immunoblot and ELISA, respectively. Neither of these molecules were detectable in BAL from null or wild-type animals by these means (not shown).

To address the issue of compensation in the null lungs by other members of the TIMP family, we performed reverse zymographic analysis on the same samples (Figure 7b). This analysis demonstrated the presence of two gelatin-protecting bands at approximately 28 and $22 \mathrm{kDa}$, which represent TIMP-1 and -2 . Coomassie staining of a parallel gel without substrate (Figure 7c) showed that the bands in the reverse zymograph represent MMP inhibitory activities and not protein bands within the BAL and also demonstrate comparable loading between samples.

Northern blot analysis of null heart, kidney, and lung mRNA did not detect compensation for the loss of Timp-3 by upregulation of other Timp family member mRNAs (Figure 8). The mRNAs encoding Collagen-I and $-I V$, however, did exhibit some interesting patterns of expression. The Collagen-I transcript appeared to be upregulated in null heart and kidney at 2 months of age, but was not detectable in aged animals. Inversely, the Collagen-IV transcript appeared to be upregulated in aged null lung compared with aged heterozygotic animals as controls.

Absence of TIMP-3 beightens MMP activity in null lung. The gelatin zymographic data presented above did not detect any changes in the levels of pro-MMPs or active MMPs between animals that expressed a functional TIMP-3 protein and those that did not. However, zymographic data may not explicitly reproduce the interactions between TIMPs and MMPs in vivo. To more clearly observe the effect of TIMP-3 deletion on MMP activity, we employed in situ zymography. Fresh-frozen lung sections from aged animals were overlaid with gelatin conjugated to quenched fluorescein. Fluorescence indicates cleavage of gelatin and release of the fluo-

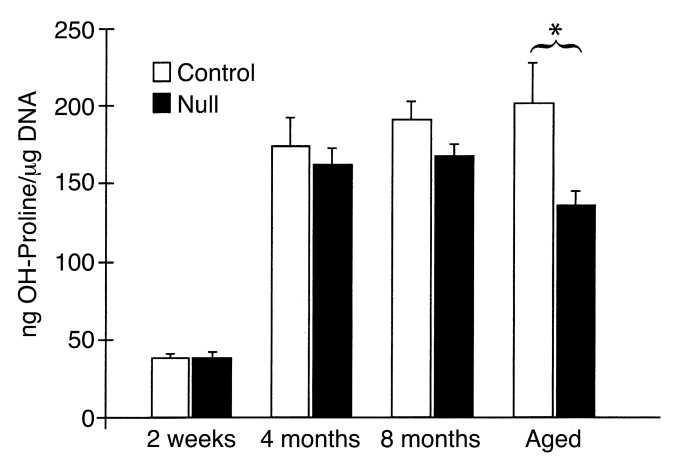

Figure 4

Collagen is reduced in the lungs of knockout mice. Hydroxy-proline content was measured in lung extracts from null and control mouse lungs at various ages (in triplicate, \pm SEM). Only the aged null mice showed a significant reduction in hydroxy-proline when normalized to extracted DNA $\left({ }^{*} P<0.02\right)$. 


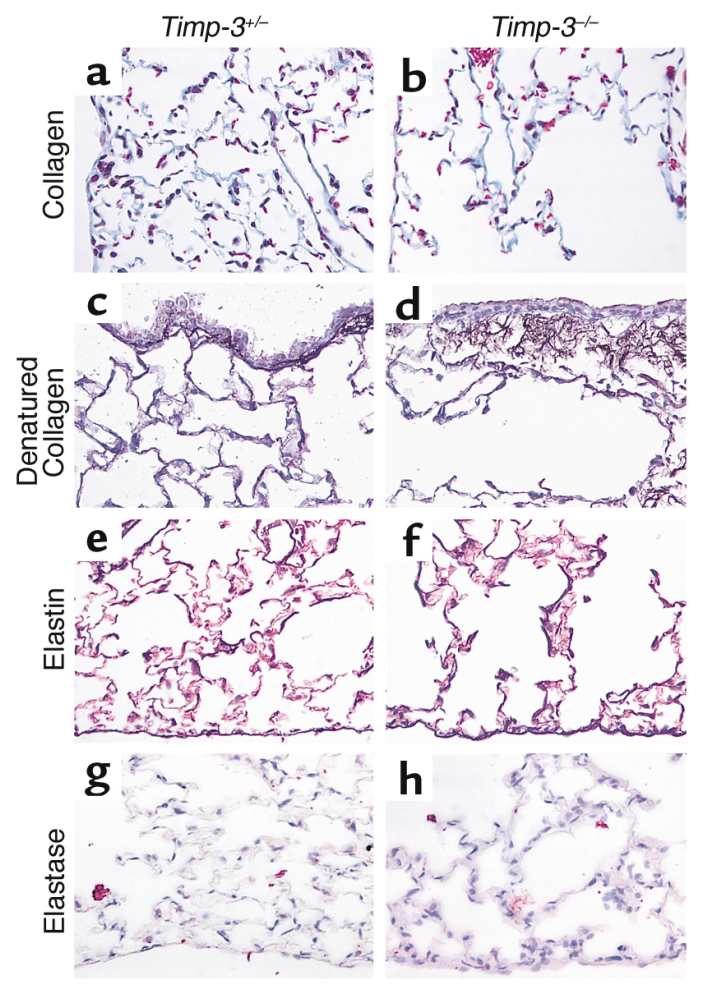

rochrome. Comparison of three different aged nulllung animals with either a wild-type or heterozygotic control demonstrated enhanced proteolysis in the null lung (Figure 9). In particular, MMP activity was seen in both the alveolar interstitium (Figure 9, $c$ and e) and the peribronchiolar regions (Figure 9, $\mathrm{d}$ and $\mathrm{e}$ ) in null lung. These observations agree with the findings presented above, which show both alveolar enlargement (Figures 3 and 5) and fragmentation of peribronchiolar collagen (Figure 5). Confirmation that the cleavage was due to MMPs was achieved by addition of GM6001 to a parallel null-lung section, which reduced the signal to background levels (Figure 9f). Although conventional electrophoretic zymography failed to demonstrate elevated MMP activities, heightened MMP activity was visualized in vivo in the absence of TIMP-3 by in situ zymography.

Null fibroblast cultures demonstrate enhanced ECM proteolysis. We turned to an in vitro system to functionally evaluate ECM homeostasis in the absence of TIMP-3. Immortal fibroblast cultures were developed from TIMP-3-null and wild-type littermates at day 16.5 of embryogenesis. While both wild-type and null fibroblast cultures syn-

\section{Figure 6}

TEM of wild-type and null aged alveolar interstitium. (a) Uniformly parallel collagen bundles and diffusely staining elastin fibers (dark areas) in a heterozygotic animal at 17 months of age (scale bar, $500 \mathrm{~nm}$ ). (b) Disorganized collagen bundles (arrowhead) but an intact basement membrane (arrows) are evident in null littermate (scale bar, $2 \mu \mathrm{m}$ ). (c) High magnification of disorganized collagen fibers (arrowhead) in independent null littermate (scale bar, $500 \mathrm{~nm}$ ). (d) Higher magnification of area shown in b. Arrows identify intact basement membrane (scale bar, $=500 \mathrm{~nm}$ ).

\section{Figure 5}

ECM and metalloelastase-specific stains. Intensity of collagen (trichrome) and elastin (Movat's stain) fiber staining was not appreciably reduced in null lung compared with control (a versus $\mathbf{b}$, and $\mathbf{e}$ versus f); however, the total area of staining represented in the micrographs was reduced in conjunction with reduced number of alveolar walls in null lung. Denatured (fragmented) collagen type-l is clearly elevated in peribronchiolar regions of null lung (c versus d). Immunostaining with a metalloelastase-specific (MMP-12) Ab identified macrophage cells. We did not note a difference in extent of macrophage infiltration in null versus control ( $\mathbf{g}$ versus $\mathbf{h}$ ) by this method or by TEM (Figure 6). All animals were littermates at 13 months of age.

thesize and secrete collagen type-I, Western blot analysis using an anti-collagen type-I Ab demonstrated that within the ECM derived from null cultures the majority of collagen type-I was degraded (Figure 10a). The reduction in abundance of the full-length chains (upper doublet) in the null ECM was accompanied by the generation of a cleavage product of lower molecular weight (three-quarter fragment). This enhanced cleavage of collagen type-I in the null ECM could be partially rescued by the addition of GM6001 to the null culture. Analysis with anti-collagen type-IV Ab showed that the abundance of this ECM molecule was also substantially reduced in null ECM when compared with wild-type culture ECM (Figure 10b). Likewise, degradation of collagen type-IV in null ECM could be partially rescued by the addition of GM6001. Silver stain analysis revealed a generalized reduction in the ECM content in null versus wild-type cultures (Figure 10c). This is evidently due to degradation in null cultures rather than enhanced synthesis in wildtype cultures because inhibition of MMP activity in the null culture substantially protected ECM proteins from degradation (Figure 10c).

\section{Discussion}

We have shown that disruption of the proteolytic balance between MMPs and their endogenous inhibitors, the TIMPs, affects lung structure and function. Dele-
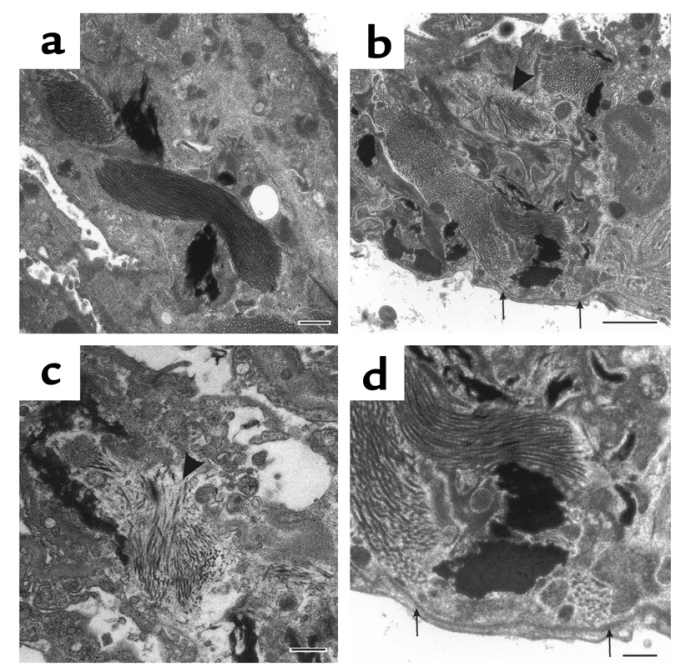


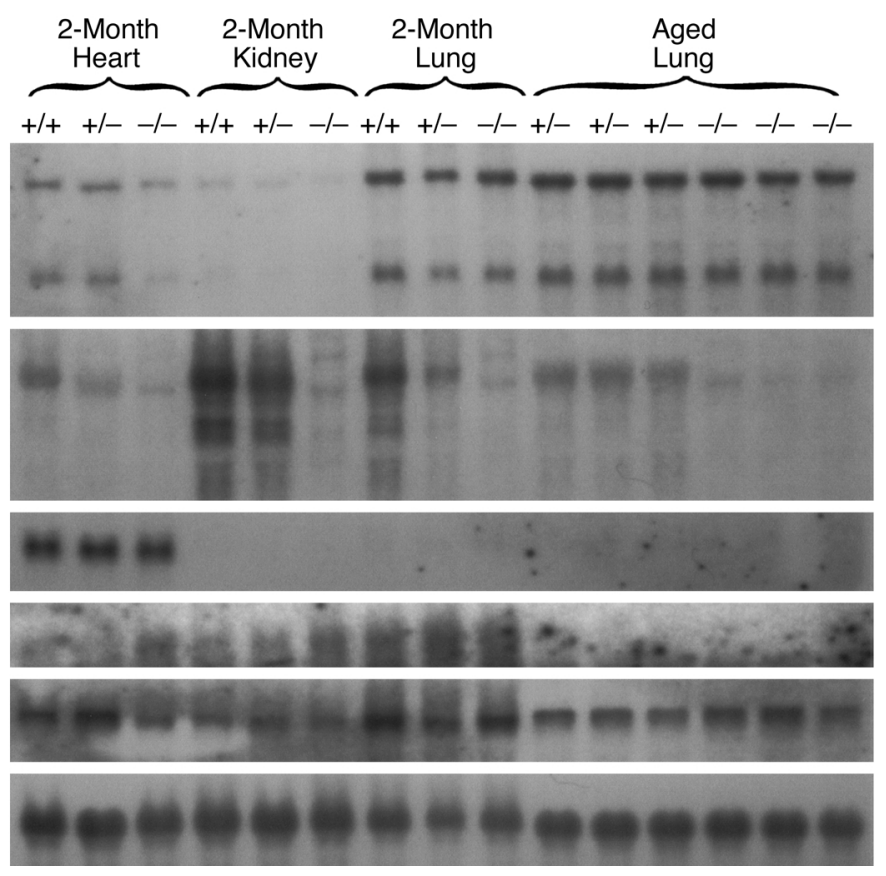

Figure 7

Zymographic and reverse zymographic analysis of BAL fluid. (a) Zymographic analysis of wild-type and null BAL at 2 and 5 months of age. No differences in MMP-

Timp-2

Timp-3

Timp-4

Collagen-I

Collagen-IV

185 tion of the Timp-3 gene and protein activity has yielded a unique mouse model that exhibits destruction of the ECM and a corresponding decrease in the physiological function of the lungs of aged null mice. TIMP-3-null mutant mice demonstrate a progressive enlargement of alveolar air space area with increasing age, culminating in incapacitating illness and a shorter life span.

The increase in alveolar size seen in null animals appears to be a direct result of alterations in ECM turnover due to deletion of the TIMP-3 protein. The abundance of collagen in the mammalian lung normally increases rapidly during the perinatal and postnatal period, with collagen concentration increasing five- to tenfold between birth and adulthood (74). Consistent with this, hydroxy-proline content of both null and wild-type animals does indeed increase dramatically between 2 weeks and 4 months of age. The hydroxy-proline assay employed in these experiments detects all forms of collagen, but the

\footnotetext{
Figure 8

Northern blot analysis of heart, kidney, and lung mRNA. We did not observe enhanced abundance of either Timp- 2 or Timp- 4 mRNAs in this investigation in any tissue at either 2 months or in lungs from aged animals. The Timp-1 mRNA was not detected in this experiment. The transcript encoding Collagen type-I appears to be upregulated in the heart and kidney at 2 months of age. Collagen type-IV mRNA appears to be upregulated in the aged null lung. The 185 control shows approximately equal loading between samples.
}
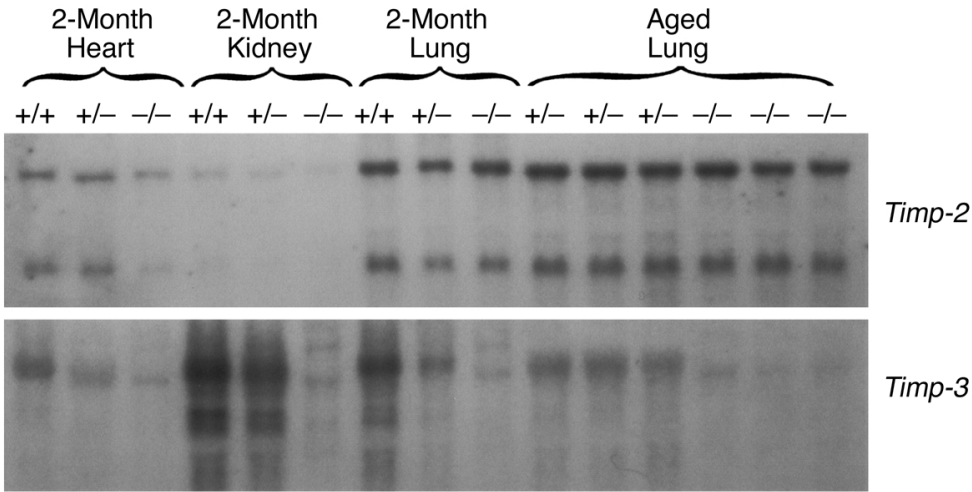

Timp-3
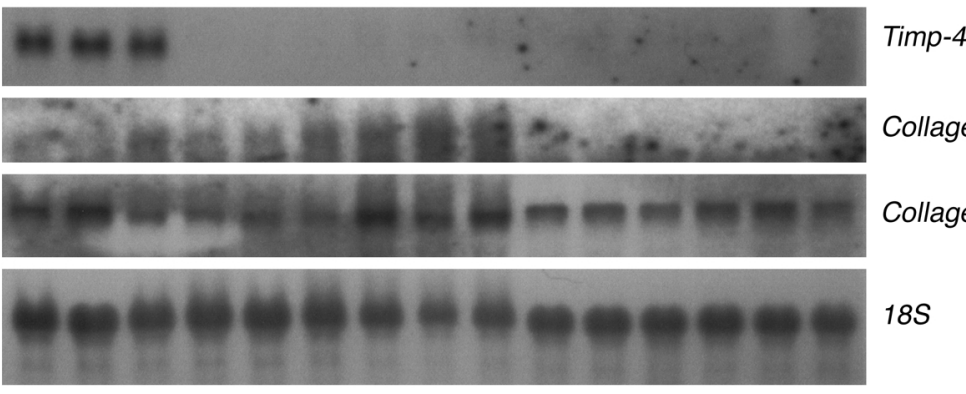

reduction in collagen content presumably reflects a reduction in structural collagens. Fibrillar type-I and -III collagen (in a ratio of 2:1) represent approximately $90 \%$ of total collagen content in adult mammalian lung $(75,76)$ and are found throughout the interstitium of alveolar structures (77).

The reduction in hydroxy-proline content seen in aged TIMP-3-null animals likely indicates a loss of these structural collagens due to uninhibited MMP proteolytic activity. This interpretation is strengthened by histological data that show enhanced staining for fragmented collagens in peribronchiolar regions of 

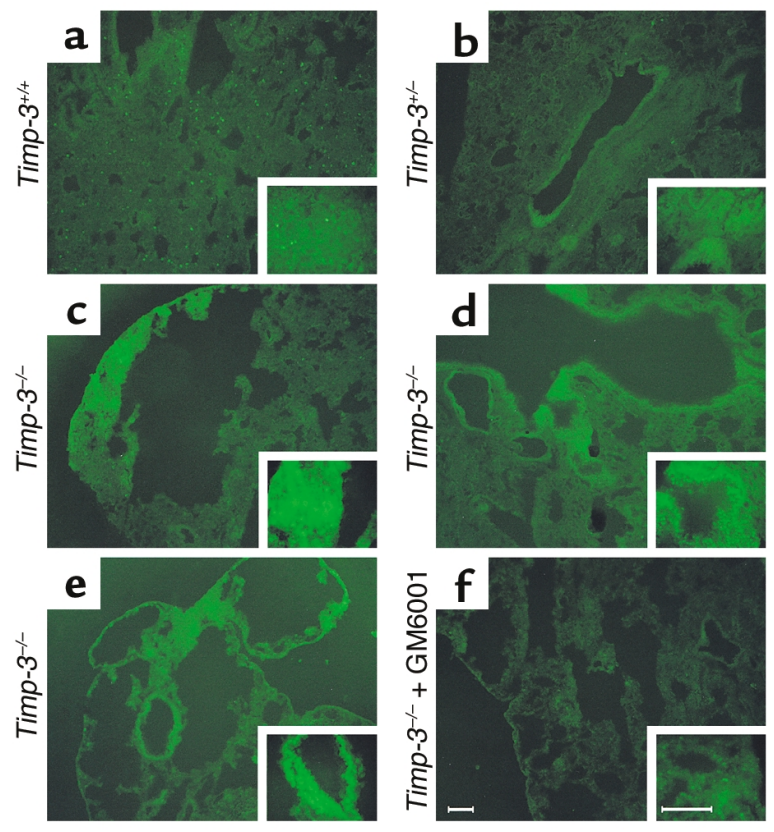

aged null lungs. Furthermore, electron microscopic analysis of lungs from aged TIMP-3-deficient mice demonstrated the presence of disordered collagen typeI bundles within alveolar walls. This suggests there is turnover of fibrillar collagen within the interstitium of alveoli, with consequent synthesis and assembly of disorganized fibers. Ultrastructural studies from human emphysema biopsy samples have demonstrated that alveolar enlargement is associated with randomized collagen fibrils, whereas normal alveolar septa contained uniformly parallel fibrils (78). Proof of principle that altered collagen homeostasis can occur in the absence of TIMP-3 was provided by in vitro experiments, where both collagen type-I and collagen-type IV were shown to be preferentially degraded in null fibroblast cultures. This defect is likely due to loss of TIMP-3 activity, since addition of the synthetic MMP inhibitor GM6001 could partially rescue the ECM degradation in null fibroblast cultures. Electron microscopy demonstrated basement membranes were not degraded in null lung, which may reflect the elevated abundance of Collagen type-IV mRNA in aged null lung.

\section{Figure 10}

Western blot analysis of fibroblast culture ECM. (a) Intact collagen typeI (upper doublet; 120 and $125 \mathrm{kDa}$ ) was reduced TIMP-3-null fibroblast culture ECM with a corresponding appearance of an approximately 90 $\mathrm{kDa}$ degradation fragment (three-quarter fragment). Collagen type-I degradation was partially rescued by the addition of GM6601 to the null culture. (b) Intact collagen type-IV abundance was reduced in the ECM collected from null fibroblasts compared with control cells. Addition of GM6001 to inhibit MMPs in the null cultures partially rescued the degradation. (c) Silver-stained SDS-PAGE gel demonstrating a global reduction in protein abundance in null ECM again partially reversible by the addition of GM6001 to null cultures.

\section{Figure 9}

In situ zymographic analysis of fresh-frozen, noninflated, control and null aged lung. (a) Wild-type lung section demonstrating minimal MMP activity in either the alveolar interstitium or the peribronchiolar regions (upper left corner), represented by cleavage of quenched FITC from a gelatin substrate and subsequent fluorescence. This particular animal appeared to have a higher than usual infiltration of macrophage cells, shown by the focal fluorescence throughout the tissue. Insets show higher magnification. (b) Heterozygotic lung showing slightly elevated MMP activity surrounding a bronchiole. (c) Alveolar interstitium demonstrates heightened MMP activity in the null lung. (d and $\mathbf{e}$ ) Independent null littermates showing elevated peribronchiolar and interstitial MMP activity. (f) Same animal represented in e, except with the addition of synthetic inhibitor (GM6001) added to the substrate. This negative control demonstrates the majority of the gelatinolytic activity in the null lung is due to MMPs (scale bars, $100 \mu \mathrm{m}$ ).

Unlike the other three TIMP proteins, TIMP-3 is not freely diffusable but rather binds to the $\operatorname{ECM}(21,23)$ by glycosaminoglycans such as heparin, heparin sulfate, and chondroitin sulfate (24), which places TIMP-3 in an ideal location for regulating activities of activated MMPs. Electrophoretic gelatin zymography employed to analyze MMP activity is limited in scope because the extraction procedure can not recapitulate potential TIMP-MMP interactions occurring in vivo. We therefore performed in situ zymography using fresh-frozen sections of aged TIMP-3-null lung and demonstrated in vivo that MMP activity is enhanced within null-lung tissue compared with controls.

We propose a mechanism by which deletion of TIMP-3 in the lung shifts the TIMP/MMP balance to favor MMP-mediated destruction of lung ECM. In the lung, the net effect appears to be reduced abundance of

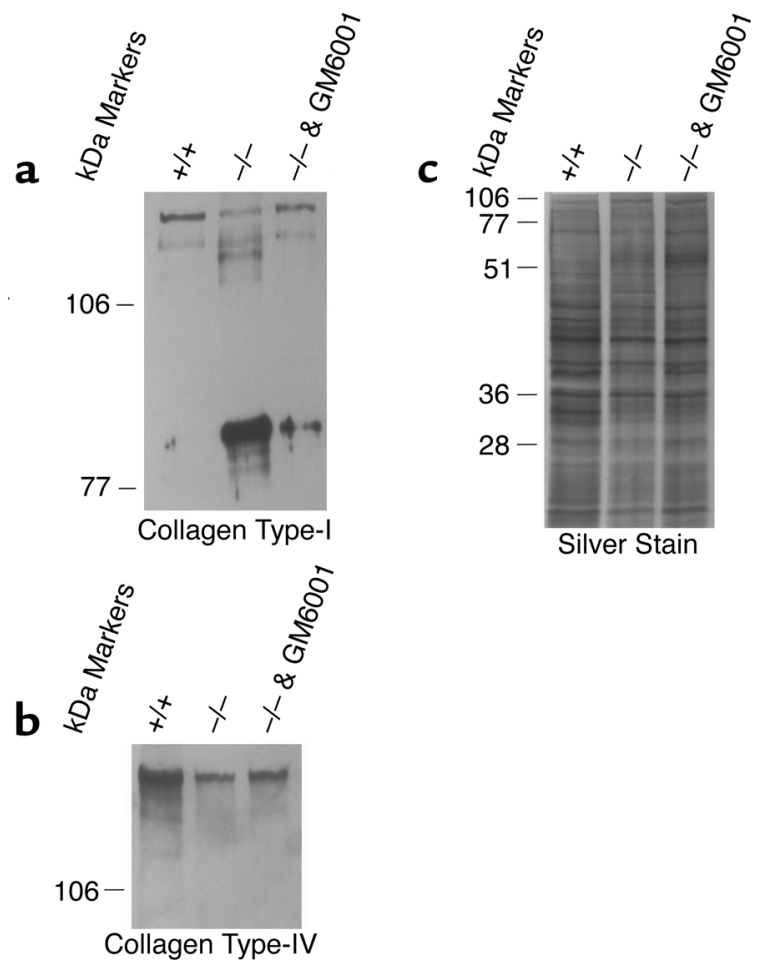


collagen type-I in aged null animals (as measured biochemically), and replacement synthesis of disorganized collagen fibrils in the alveolar interstitium (as in the electron micrographs) over the lifetime of null animals. Consequent reduction in the mechanical strength of alveolar interstitium may result in disruption of alveolar structure and the observed enlargement of alveolar air spaces that progress with increasing age of the animal. In aged null animals, the physiological manifestation of reduced alveolar surface area is reflected in reduced efficiency of carbon monoxide uptake.

We were not able to demonstrate a statistically significant decrease in total elastin content in null lungs by biochemical means (hot alkali method of elastin extraction; not shown), histological staining, or electron microscopy. Furthermore, we were not able to detect enhanced infiltration of metalloelastase-expressing macrophage cells in TIMP-3-deficient lungs when compared with controls. Also, neither TACE nor soluble TNF- $\alpha$ levels were detectable in these lungs. These data imply that while the collagen matrix in null lungs may be susceptible to turnover in the absence of TIMP-3, elastin ultrastructure is relatively impervious to attack. In this regard, our model differs from established models of pulmonary emphysema. Tobacco smoke-induced emphysema in guinea pigs is associated with increased MMP-1 expression in macrophages as well as alveolar epithelial and fibroblast cells (79), and is also associated with abnormal collagen breakdown and repair (80). Surfactant D-null mice (81) provide evidence that increased MMP-2, -9 , and -12 activity can be causative in the development of the disease and D'Armiento and coworkers have demonstrated that overexpression of MMP-1 in the lungs of transgenic mice results in early onset pulmonary emphysema (19). However, pulmonary emphysema due to chronic exposure to cigarette smoke induces an inflammatory response with accumulation of macrophage and neutrophil cells in respiratory bronchioles and alveolar spaces. The release of proteinases from inflammatory cells results in destruction of alveolar ECM, with disruption of elastin fibers essential to the air space enlargement associated with emphysema (82). Finally, mice deficient for MMP-12 are resistant to cigarette smoke-induced emphysema. Thus, MMP-12 produced by alveolar macrophages and consequent destruction of elastin fibers appears to be essential in development of the disease (20).

While we were not able to demonstrate an increase in macrophage infiltration or decrease in the total amount of elastin in the lungs of TIMP-3-null mice, light microscopy did demonstrate disruption of alveolar walls, and Movat's stain showed that elastin fibers were separated in the detached walls. This may represent focal dissolution of elastin fibers by heightened MMP proteolysis in the absence of TIMP-3 or could result from mechanical shearing of elastin fibers in vivo following disruption of collagen bundles and weakening of alveolar interstitial tensile strength. Although we did observe activated MMP-12 in both the wild-type and null BAL fluid by immunoblot analysis (not shown), additional experiments are necessary to precisely define whether the nature of the elastin defect is a primary consequence of heightened MMP activity or a secondary effect of loss of organized collagen structure.

The progressive nature of the air space enlargement with increasing age of the null animals supports the hypothesis that absence of TIMP-3 inhibitory activity results in the gradual degradation of ECM. Resident fibroblasts within the interstitium of the lung could provide a source of MMP-2 and -9. Likewise, macrophage cells normally present in the lung (83) may contribute MMP-12. MMP-2 is able to degrade fibrillar collagens (84), and MMP-2, -9 , and -12 are capable of cleaving elastin (85). Taken together, these MMPs, in the absence of TIMP-3, may damage the collagen and elastin ultrastructure of the null lung over the long term, which then leads to loss of alveolar structure, coalescence of alveoli to form larger air spaces with the consequence of decreased lung efficiency, and a shortened life span. While our findings are consistent with the conclusion that the MMP/TIMP axis is perturbed in the TIMP-3-null animals, one cannot rule out additional effects on ADAM/ADAM-TS activity in the lung. Future experiments will address how the deletion of TIMP-3 impacts the pathogenesis of emphysema and the processes of inflammatory cell infiltration in response to cigarette smoke or instillation of monocyte/ macrophage chemotactic peptides.

\section{Acknowledgments}

This work was supported by grants from the Human Frontiers of Science Program (RG 549/95-M to R. Khokha), the Canadian Institutes of Health Research (14782 to R. Khokha and 37927 to K.J. Leco), the Academic Development Fund of the University of Western Ontario (00-119 to K.J. Leco), and the Canada Foundation for Innovation (K.J. Leco). Postdoctoral salary support for K.J. Leco was provided by an Amgen Postdoctoral Fellowship and Helena H. Lam Postdoctoral fellowship. The authors thank Vasek Pitelka for technical assistance and Pamela Leco for typographical and editorial assistance with the manuscript.

\footnotetext{
1. Lukashev, M.E., and Werb, Z. 1998. ECM signalling: orchestrating cell behaviour and misbehaviour. Trends Cell Biol. 8:437-441.

2. Birkedal-Hansen, H., et al. 1993. Matrix metalloproteinases: a review. Crit. Rev. Oral Biol. Med. 4:197-250.

3. Matrisian, L.M. 1992. The matrix-degrading metalloproteinases. Bioessays. 14:455-463.

4. Leco, K.J., et al. 1997. Murine tissue inhibitor of metalloproteinases-4 (Timp-4): cDNA isolation and expression in adult mouse tissues. FEBS Lett. 401:213-217.

5. Greene, J., et al. 1996. Molecular cloning and characterization of human tissue inhibitor of metalloproteinase 4. J. Biol. Chem. 271:30375-30380.

6. Salo, T., Makela, M., Kylmaniemi, M., Autio-Harmainen, H., and Larjava, H. 1994. Expression of matrix metalloproteinase-2 and -9 during early human wound healing. Lab. Invest. 70:176-182.

7. Inderdeo, D.S., Edwards, D.R., Han, V.K., and Khokha, R. 1996. Temporal and spatial expression of tissue inhibitors of metalloproteinases during the natural ovulatory cycle of the mouse. Biol. Reprod. 55:498-508. 8. Nothnick, W.B., Edwards, D.R., Leco, K.J., and Curry, T.E.J. 1995. Expres-
} 
sion and activity of ovarian tissue inhibitors of metalloproteinases during pseudopregnancy in the rat. Biol. Reprod. 53:684-691.

9. Harvey, M.B., et al. 1995. Proteinase expression in early mouse embryos is regulated by leukaemia inhibitory factor and epidermal growth factor. Development. 121:1005-1014.

10. Reponen, P., et al. 1995. 92-kDa type IV collagenase and TIMP-3, but not 72-kDa type IV collagenase or TIMP-1 or TIMP-2, are highly expressed during mouse embryo implantation. Dev. Dyn. 202:388-396.

11. Alexander, C.M., et al. 1996. Expression and function of matrix metalloproteinases and their inhibitors at the maternal-embryonic boundary during mouse embryo implantation. Development. 122:1723-1736.

12. Leco, K.J., Edwards, D.R., and Schultz, G.A. 1996. Tissue inhibitor of metalloproteinases-3 is the major metalloproteinase inhibitor in the decidualizing murine uterus. Mol. Reprod. Dev. 45:458-465.

13. Fata, J.E., Leco, K.J., Moorehead, R.A., Martin, D.C., and Khokha, R. 1999. TIMP-1 is important for epithelial proliferation and branching morphogenesis during mouse mammary development. Dev. Biol. 211:238-254.

14. Talhouk, R.S., Bissell, M.J., and Werb, Z. 1992. Coordinated expression of extracellular matrix-degrading proteinases and their inhibitors regulates mammary epithelial function during involution. J. Cell Biol. 118:1271-1282.

15. Lund, L.R., et al. 1996. Two distinct phases of apoptosis in mammary gland involution: proteinase- independent and -dependent pathways. Development. 122:181-193.

16. Gunja-Smith, Z., Morales, A.R., Romanelli, R., and Woessner,J.F.J. 1996 Remodeling of human myocardial collagen in idiopathic dilated cardiomyopathy. Role of metalloproteinases and pyridinoline cross-links. Am. J. Pathol. 148:1639-1648.

17. Kruger, A., et al. 1998. Host TIMP-1 overexpression confers resistance to experimental brain metastasis of a fibrosarcoma cell line. Oncogene. 16:2419-2423.

18. Kruger, A., Fata, J.E., and Khokha, R. 1997. Altered tumor growth and metastasis of a T-cell lymphoma in Timp-1 transgenic mice. Blood. 90:1993-2000.

19. D’Armiento, J., Dalal, S.S., Okada, Y., Berg, R.A., and Chada, K. 1992. Collagenase expression in the lungs of transgenic mice causes pulmonary emphysema. Cell. 71:955-961.

20. Hautamaki, R.D., Kobayashi, D.K., Senior, R.M., and Shapiro, S.D. 1997. Requirement for macrophage elastase for cigarette smoke-induced emphysema in mice. Science. 277:2002-2004.

21. Blenis, J., and Hawkes, S.P. 1983. Transformation-sensitive protein associated with the cell substratum of chicken embryo fibroblasts. Proc. Natl. Acad. Sci. USA. 80:770-774.

22. Pavloff, N., Staskus, P.W., Kishnani, N.S., and Hawkes, S.P. 1992. A new inhibitor of metalloproteinases from chicken: ChIMP-3. A third member of the TIMP family. J. Biol. Chem. 267:17321-17326.

23. Leco, K.J., Khokha, R., Pavloff, N., Hawkes, S.P., and Edwards, D.R. 1994 Tissue inhibitor of metalloproteinases-3 (TIMP-3) is an extracellular matrix-associated protein with a distinctive pattern of expression in mouse cells and tissues. J. Biol. Chem. 269:9352-9360.

24. Yu, W.-H., Yu, S.-S., Meng, Q., Brew, K., and Woessner, J.F., Jr. 2000. TIMP-3 binds to sulfated glycosaminoglycans of the extracellular matrix. J. Biol. Chem. 275:31226-31232.

25. Apte, S.S., Olsen, B.R., and Murphy, G. 1995. The gene structure if tissue inhibitor of metalloproteinases (TIMP)-3 and its inhibitory activities define the distinct TIMP gene family. J. Biol. Chem. 270:14313-14318.

26. Apte, S.S., et al. 1994. Gene encoding a novel murine tissue inhibitor of metalloproteinases (TIMP), TIMP-3, is expressed in developing mouse epithelia, cartilage, and muscle, and is located on mouse chromosome 10. Dev. Dyn. 200:177-197.

27. Yang, T.T., and Hawkes, S.P. 1992. Role of the $21-\mathrm{kDa}$ protein TIMP-3 in oncogenic transformation of cultured chicken embryo fibroblasts. Proc. Natl. Acad. Sci. USA. 89:10676-10680.

28. Castagnino, P., Soriano, J.V., Montesano, R., and Bottaro, D.P. 1998 Induction of tissue inhibitor of metalloproteinases-3 is a delayed early cellular response to hepatocyte growth factor. Oncogene. 17:481-492.

29. Bian, J., et al. 1996. Suppression of in vivo tumor growth and induction of suspension cell death by tissue inhibitor of metalloproteinases (TIMP)-3. Carcinogenesis. 17:1805-1811.

30. Ahonen, M., Baker, A.H., and Kahari, V.M. 1998. Adenovirus-mediated gene delivery of tissue inhibitor of metalloproteinases-3 inhibits invasion and induces apoptosis in melanoma cells. Cancer Res. 58:2310-2315.

31. Smith, M.R., Kung, H., Durum, S.K., Colburn, N.H., and Sun, Y. 1997. TIMP-3 induces cell death by stabilizing TNF-alpha receptors on the surface of human colon carcinoma cells. Cytokine. 9:770-780.

32. Baker, A.H., George, S.J., Zaltsman, A.B., Murphy, G., and Newby, A.C. 1999. Inhibition of invasion and induction of apoptotic cell death of cancer cell lines by overexpression of TIMP-3. Br. J. Cancer. 79:1347-1355.

33. Baker, A.H., Zaltsman, A.B., George, S.J., and Newby, A.C. 1998. Divergent effects of tissue inhibitor of metalloproteinase- $1,-2$, or -3 overexpression on rat vascular smooth muscle cell invasion, proliferation, and death in vitro. TIMP-3 promotes apoptosis. J. Clin. Invest. 101:1478-1487.
34. George, S.J., Lloyd, C.T., Angelini, G.D., Newby, A.C., Baker, A.H. 2000. Inhibition of late vein graft neointima formation in human and porcine models by adenovirus-mediated overexpression of tissue inhibitor of metalloproteinase-3. Circulation. 101:296-304.

35. Bond, M., et al. 2000. Localization of the death domain of tissue inhibitor of metalloproteinase- 3 to the $\mathrm{N}$ terminus. Metalloproteinase inhibition is associated with proapoptotic activity. J. Biol. Chem. 275:41358-41363.

36. Blobel, CP. 1997. Metalloprotease-disintegrins: links to cell adhesion and cleavage of TNF alpha and Notch. Cell. 90:589-592.

37. Black, R.A., and White, J.M. 1998. ADAMs: focus on the protease domain. Curr. Opin. Cell Biol. 5:654-659.

38. Amour, A., et al. 2000. The in vitro activity of ADAM-10 is inhibited by TIMP-1 and TIMP-3. FEBS Lett. 473:275-279.

39 Hashimoto, G., Aoki, T., Nakamura, H., Tanzawa, K., and Okada, Y. 2001. Inhibition of ADAMTS4 (aggrecanase-1) by tissue inhibitors of metalloproteinases (TIMP-1, 2, 3 and 4). FEBS Lett. 494:192-195.

40. Kashiwagi, M., Tortorella, M., Nagase, H., and Brew, K. 2001. Timp-3 is a potent inhibitor of aggrecanase 1 (adam-ts4) and aggrecanase 2 (adamts5). J. Biol. Chem. 276:12501-12504.

41. Loechel, F., Fox, J.W., Murphy, G., Albrechtsen, R., and Wewer, U.M. 2000. ADAM 12-S cleaves IGFBP-3 and IGFBP-5 and is inhibited by TIMP-3. Biochem. Biophys. Res. Commun. 278:511-515.

42. Amour, A., et al. 1998. TNF-alpha converting enzyme (TACE) is inhibited by TIMP-3. FEBS Lett. 435:39-44.

43. Lee, M.H., Knauper, V., Becherer, J.D., and Murphy, G. 2001. Full-length and N-TIMP-3 display equal inhibitory activities toward TNF-alpha convertase. Biochem. Biophys. Res. Commun. 280:945-950.

44. Hargreaves, P.G., et al. 1998. Human myeloma cells shed the interleukin6 receptor: inhibition by tissue inhibitor of metalloproteinase- 3 and a hydroxamate-based metalloproteinase inhibitor. Br. J. Haematol. 101:694-702.

45. Borland, G., Murphy, G., and Ager, A. 1999. Tissue inhibitor of metalloproteinases-3 inhibits shedding of L-selectin from leukocytes. J. Biol. Chem. 274:2810-2815.

46. Fitzgerald, M.L., Wang, Z., Park, P.W., Murphy, G., and Bernfield, M. 2000 . Shedding of syndecan- 1 and -4 ectodomains is regulated by multiple signaling pathways and mediated by a TIMP-3-sensitive metalloproteinase. J. Cell Biol. 148:811-824.

47. Nath, D., Williamson, N.J., Jarvis, R., and Murphy, G. 2001. Shedding of c-Met is regulated by crosstalk between a G-protein coupled receptor and the EGF receptor and is mediated by a TIMP-3 sensitive metalloproteinase. J. Cell Sci. 114:1213-1220.

48. Soloway, P.D., Alexander, C.M., Werb, Z., and Jaenisch, R. 1996. Targeted mutagenesis of Timp-1 reveals that lung tumor invasion is influenced by Timp- 1 genotype of the tumor but not by that of the host. Oncogene. 13:2307-2314.

49. Nothnick, W.B., Soloway, P., and Curry, T.E. 1997. Assessment of the role of tissue inhibitor of metalloproteinase-1 (TIMP-1) during the periovulatory period in female mice lacking a functional TIMP-1 gene. Biol. Reprod. 5:1181-1188.

50. Eddy, A.A., Kim, H., Lopez-Guisa, J., Oda, T., and Soloway, P.D. 2000. Interstitial fibrosis in mice with overload proteinuria: deficiency of TIMP-1 is not protective. Kidney Int. 58:618-28.

51. Kim, H., et al. 2001. TIMP-1 deficiency does not attenuate interstitial fibrosis in obstructive nephropathy. J. Am. Soc. Nephrol. 12:736-748.

52. Nothnick, W.B., Soloway, P.D., and Curry, T.E. 1998. Pattern of messenger ribonucleic acid expression of tissue inhibitors of metalloproteinases (TIMPs) during testicular maturation in male mice lacking a functional TIMP-1 gene. Biol. Reprod. 59:364-370.

53. Nothnick, W.B. 2000. Disruption of the tissue inhibitor of metalloproteinase-1 gene results in altered reproductive cyclicity and uterine morphology in reproductive-age female mice. Biol. Reprod. 63:905-912.

54. Osiewicz, K., McGarry, M., and Soloway, P.D. 1999. Hyper-resistance to infection in TIMP-1-deficient mice is neutrophil dependent but not immune cell autonomous. Ann. NY Acad. Sci. 878:494-496.

55. Lijnen, H.R., Soloway, P., and Collen, D. 1999. Tissue inhibitor of matrix metalloproteinases-1 impairs arterial neointima formation after vascular injury in mice. Circ. Res. 85:1186-1191.

56. Roten, L., et al. 2000. Effects of gene deletion of the tissue inhibitor of the matrix metalloproteinase-type 1 (TIMP-1) on left ventricular geometry and function in mice. J. Mol. Cell. Cardiol. 32:109-120.

57. Yamada, E., et al. 2001. TIMP-1 promotes VEGF-induced neovascularization in the retina. Histol. Histopathol. 16:87-97.

58. Wang, Z., Juttermann, R., and Soloway, P.D. 2000. TIMP-2 is required for efficient activation of proMMP-2 in vivo. J. Biol. Chem. 275:26411-26415.

59. Caterina, J.J., et al. 2000. Inactivating mutation of the mouse tissue inhibitor of metalloproteinases-2 (Timp-2) gene alters proMMP-2 activation. J. Biol. Chem. 275:26416-26422.

60. Sambrook, J., Fritsch, E.F., and Maniatis, T. 1989. Molecular cloning: a laboratory manual. 2nd edition. Cold Spring Harbor Laboratory Press. Cold Spring Harbor, New York, USA. 2.60-2.66. 
61. Sun, Y., et al. 1995. Molecular cloning of mouse tissue inhibitor of metalloproteinases-3 and its promoter. J. Biol. Chem. 270:19312-19319.

62. Waterhouse, P., et al. 1995. Lymphoproliferative disorders with early lethality in mice deficient in Ctla-4. Science. 270:985-988.

63. Chomczynski, P., and Sacchi, N. 1987. Single-step method of RNA isolation by acid guanidinium thiocyanate-phenol-chloroform extraction. Anal. Biochem. 162:156-159.

64. Naum, Y., and Morgan, T.E. 1973. A microassay for elastin. Anal. Biochem. 53:392-396.

65. Creemers, L.B., Jansen, D.C., van Veen-Reurings, A., van den Bos, T., and Everts, V. 1997. Microassay for the assessment of low levels of hydroxyproline. Biotechniques. 22:656-658.

66. Leco, K.J., et al. 1992. Differential regulation of TIMP-1 and TIMP-2 mRNA expression in normal and Ha-ras-transformed murine fibroblasts. Gene. 117:209-217.

67. Yi, C.F., Gosiewska, A., Burtis, D., and Geesin, J. 2001. Incorporation of fluorescent enzyme substrates in agarose gel for in situ zymography. Anal. Biochem. 291:27-33.

68. Brew, K., Dinakarpandian, D., and Nagase, H. 2000. Tissue inhibitors of metalloproteinases: evolution, structure and function. Biochim. Biophys. Acta. 1477:267-283.

69. Fata, J.E., et al. 2001. Accelerated apoptosis in the Timp-3-deficient mammary gland. J. Clin. Invest. 108:831-841.

70. Joronen, K., Salminen, H., Glumoff, V., Savontaus, M., and Vuorio, E. 2000. Temporospatial expression of tissue inhibitors of matrix metalloproteinases-1, -2 and -3 during development, growth and aging of the mouse skeleton. Histochem. Cell Biol. 114:157-65.

71. Weber, B.H., Vogt, G., Pruett, R.C., Stohr, H., and Felbor, U. 1994. Mutations in the tissue inhibitor of metalloproteinases-3 (TIMP3) in patients with Sorsby's fundus dystrophy. Nat. Genet. 8:352-356.

72. Depledge, M.H., Collis, C.H., and Barrett, A. 1981. A technique for measuring carbon monoxide uptake in mice. Int. J. Radiat. Oncol. Biol. Phys. 7:485-489.

73. Stupfel, M., Mordelet-Dambrine, M., Vauzelle, A., and Perramon, A. 1979. Animal models and acute and long-term carbon monoxide intoxication. Prev. Med. 8:333-334.
74. Mays, P.K., McAnulty, R.J., and Laurent, G.J. 1989. Age-related changes in lung collagen metabolism. A role for degradation in regulating lung collagen production. Am. Rev. Respir. Dis. 140:410-416.

75. Rennard, S.I., and Crystal, R.G. 1982. Lung. In Collagen in health and disease. J.B. Weiss and M.I.V. Jayson, editors. Churchill Livingstone. London, United Kingdom. 424-444.

76. Kirk, J.M.E., Heard, B.E., Kerr, I., Turner-Warwick, M., and Laurent, G.J. 1984. Quantitation of types I and III collagen in biopsy lung samples from patients with cryptogenic fibrosing alveolitis. Coll. Relat. Res. 4:169-182.

77. Madri, J.A., and Furthmayr, H. 1980. Collagen polymorphism in the lung: an immunochemical study of pulmonary fibrosis. Hum. Pathol. 11:353-366.

78. Belton, J.C., Crise, N., McLaughlin, R.F., Jr., and Tueller, E.E. 1977. Ultrastructural alterations in collagen associated with microscopic foci of human emphysema. Hum. Pathol. 8:669-677.

79. Selman, M., et al. 1996. Tobacco smoke-induced lung emphysema in guinea pigs is associated with increased interstitial collagenase. Am. J. Physiol. 271:L734-L743.

80. Wright, J.L., and Churg, A. 1995. Smoke-induced emphysema in guinea pigs is associated with morphometric evidence of collagen breakdown and repair. Am. J. Physiol. 268:L17-L20.

81. Wert, S.E., et al. 2000. Increased metalloproteinase activity, oxidant production, and emphysema in surfactant protein $\mathrm{D}$ gene-activated mice. Proc. Natl. Acad. Sci. USA. 97:5972-5977.

82. Senior, R.M., and Shapiro, S.D. 1998. Chronic obstructive pulmonary disease: epidemiology, pathophysiology, and pathogenesis. In Fishman's pulmonary diseases and disorders. 3rd edition. A.P. Fishman, editor. McGraw-Hill. New York, New York, USA. 659-681.

83. Shapiro, SD. 1998. Matrix metalloproteinase degradation of extracellular matrix: biological consequences. Curr. Opin. Cell Biol. 10:602-608.

84. Aimes, R.T., and Quigley, J.P. 1995. Matrix metalloproteinase-2 is an interstitial collagenase. J. Biol. Chem. 270:5872-5876.

85. Senior, R.M., et al. 1991. Human 92- and 72-kilodalton type IV collagenases are elastases. J. Biol. Chem. 266:7870-7875. 